\title{
Computational Intelligence-Based Optimization Methods for Power Quality and Dynamic Response Enhancement of ac Microgrids
}

\author{
Touqeer Ahmed Jumani ${ }^{1,2}$, Mohd Wazir Mustafa ${ }^{1}$, Nawaf N. Hamadneh ${ }^{3}$, \\ Samer H. Atawneh ${ }^{4}{ }^{(D}$, Madihah Md. Rasid ${ }^{1}$, Nayyar Hussain Mirjat ${ }^{5}$, \\ Muhammad Akram Bhayo ${ }^{6}$ and Ilyas Khan ${ }^{7, *}$ \\ 1 School of Electrical Engineering, Universiti Teknologi Malaysia, Skudai, Johor Bahru 81310, Malaysia; \\ atouqeer2@graduate.utm.my (T.A.J.); wazir@fke.utm.my (M.W.M.); madihah@fke.utm.my (M.M.R.) \\ 2 Department of Electrical Engineering, Mehran University of Engineering and Technology SZAB Campus, \\ Khairpur Mirs 66020, Pakistan \\ 3 Department of Basic Sciences, College of Science and Theoretical Studies, Saudi Electronic University, \\ Riyadh 11673, Saudi Arabia; nhamadneh@seu.edu.sa \\ 4 College of Computing and Informatics, Saudi Electronic University, Riyadh 11673, Saudi Arabia; \\ satawneh@seu.edu.sa \\ 5 Department of Electrical Engineering, Mehran UET, Jamshoro 76020, Pakistan; \\ nayyar.hussain@faculty.muet.edu.pk \\ 6 Department of Electrical Engineering, Quaid-e-Awan UEST, Shaheed Benazirabad 67480, Pakistan; \\ bhayoakram@gmail.com \\ 7 Faculty of Mathematics and Statistics, Ton Duc Thang University, Ho Chi Minh City 72915, Vietnam \\ * Correspondence: ilyaskhan@tdtu.edu.vn
}

Received: 14 April 2020; Accepted: 27 June 2020; Published: 6 August 2020

\begin{abstract}
The penetration of distributed generators (DGs) in the existing power system has brought some real challenges regarding the power quality and dynamic response of the power systems. To overcome the above-mentioned issues, the researchers around the world have tried and tested different control methods among which the computational intelligence (CI) based methods have been found as most effective in mitigating the power quality and transient response problems intuitively. The significance of the mentioned optimization approaches in contemporary ac Microgrid (MG) controls can be observed from the increasing number of published articles and book chapters in the recent past. However, literature related to this important subject is scattered with no comprehensive review that provides detailed insight information on this substantial development. As such, this research work provides a detailed overview of four of the most extensively used CI-based optimization techniques, namely, artificial neural network (ANN), fuzzy logic (FL), adaptive neuro-fuzzy inference system (ANFIS) and genetic algorithm (GA) as applied in ac MG controls from 42 research articles along with their basic working mechanism, merits, and limitations. Due to space and scope constraints, this study excludes the applications of swarm intelligence-based optimization methods in the studied field of research. Each of the mentioned CI algorithms is explored for three major MG control applications i.e., reactive power compensation and power quality, MPPT and MG's voltage, frequency, and power regulation. In addition, this work provides a classification of the mentioned CI-based optimization studies based on various categories such as key study objective, optimization method applied, DGs utilized, studied MG operating mode, and considered operating conditions in order to ease the searchability and selectivity of the articles for the readers. Hence, it is envisaged that this comprehensive review will provide a valuable one-stop source of knowledge to the researchers working in the field of CI-based ac MG control architectures.
\end{abstract}


Keywords: computational intelligence; optimization; ac microgrids; power quality; dynamic response enhancement

\section{Introduction}

The graphs for electricity consumption worldwide are continuously rising with increasing modern-day necessities and rapidly increasing population; thus, causing the overloading of the existing power systems. Besides, since the conventional power systems generally consist of fossil fuel-based power plants, the increasing load also increases the fuel consumption which consequently increases the amount of greenhouse gases and hence becomes the cause of the increased environmental pollution. One of the most effective solutions to overcome the stated issues is to use a Microgrid (MG). An MG is defined as a cluster of distributed generators (DGs) and loads, with a central control system, that delivers both power and heat to the local area [1]. These DGs are interconnected to one another and with the main grid by using a non-linear device like a voltage source inverter (VSI) or voltage source converter (VSC). The major role of using these power electronic devices is to provide a controlled interface between DGs and the main grid for regulating the voltage, frequency, and desired power-sharing ratio among the connected power supplying sources [2]. Despite the vast benefits of using these interfacing devices, they pose some severe threats to the power quality of the power system. This is because of the reason that these devices are generally semi-conductor based non-linear devices which operate at very high switching frequencies, thus distorting the power quality of the supplied power [3]. A typical configuration of an MG with two DGs and a battery bank is depicted in Figure 1.

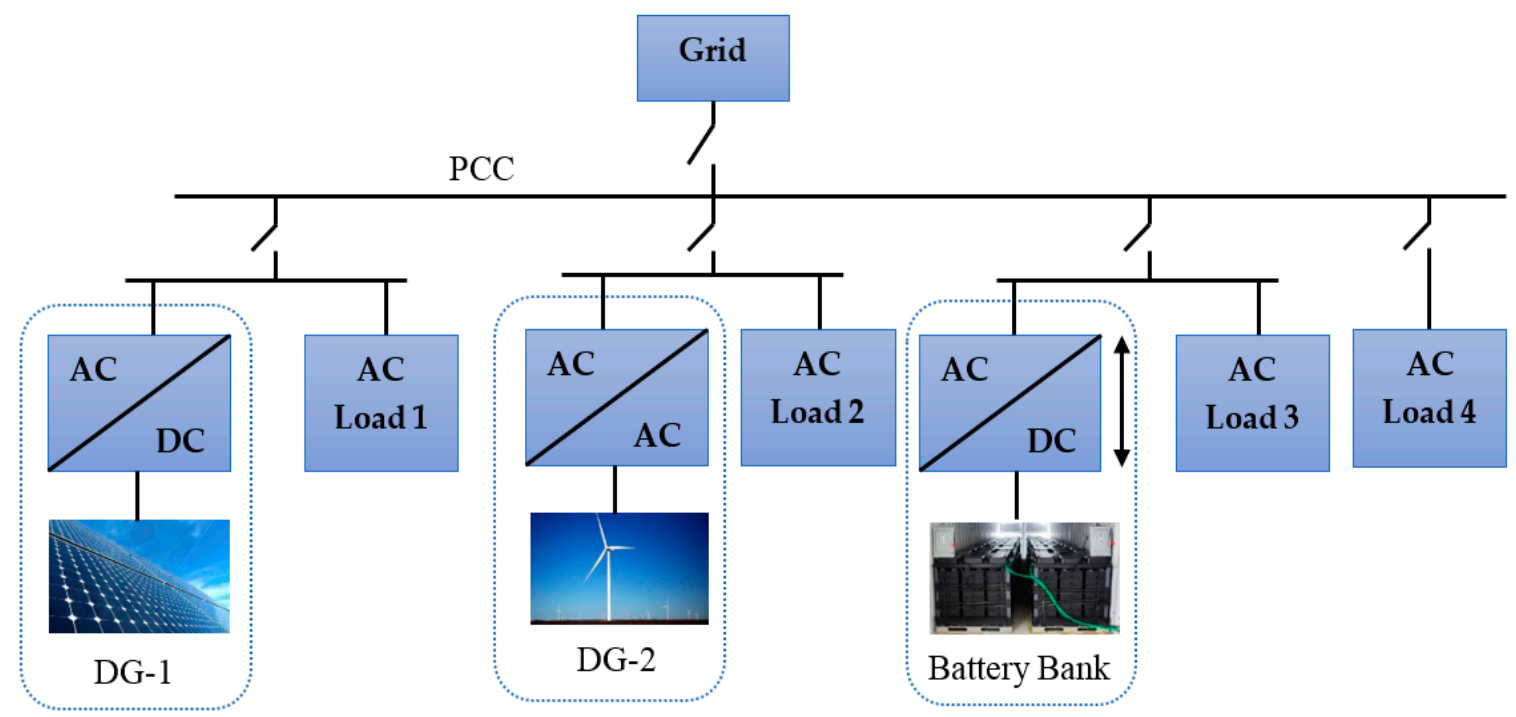

Figure 1. A basic structure of a Microgrid (MG) [4,5].

To ensure suitable power quality and smooth operation of the MG system during all operating conditions and MG operating modes, an intelligent and robust control strategy is fundamentally required. The selection of the controller parameters is also an important aspect that decides the performance of the selected controller under different MG operating conditions and system configurations. With the advancement in the field of computational intelligence (CI)-based optimization methods, the optimal values of these parameters are selected automatically which results in more robust and intelligent designs of the modern MGs [6]. Since analytical solutions for MGs are too complex and are time-consuming, therefore, optimization is generally carried out by using the CI methods in order to avoid lengthy calculations and to obtain the most optimal solutions in less time. This is especially for the optimization problems with more than one objective function that are too complex to be solved 
with polynomial-time domain-based conventional iterative methods [7]. Due to the complex nature and slower convergence of conventional iterative optimization methods, the CI-based optimization approaches have been widely adopted to achieve near-optimum solutions in a comparatively shorter time [7].

Computational intelligence is a branch of artificial intelligence that mimics human beings and nature by utilizing technology and computer science. It includes fuzzy logic control (FLC), artificial neural networks (ANN), adaptive neuro-fuzzy inference system (ANFIS), genetic algorithms (GA), and swarm-based optimization methods as depicted in Figure 2 [8].

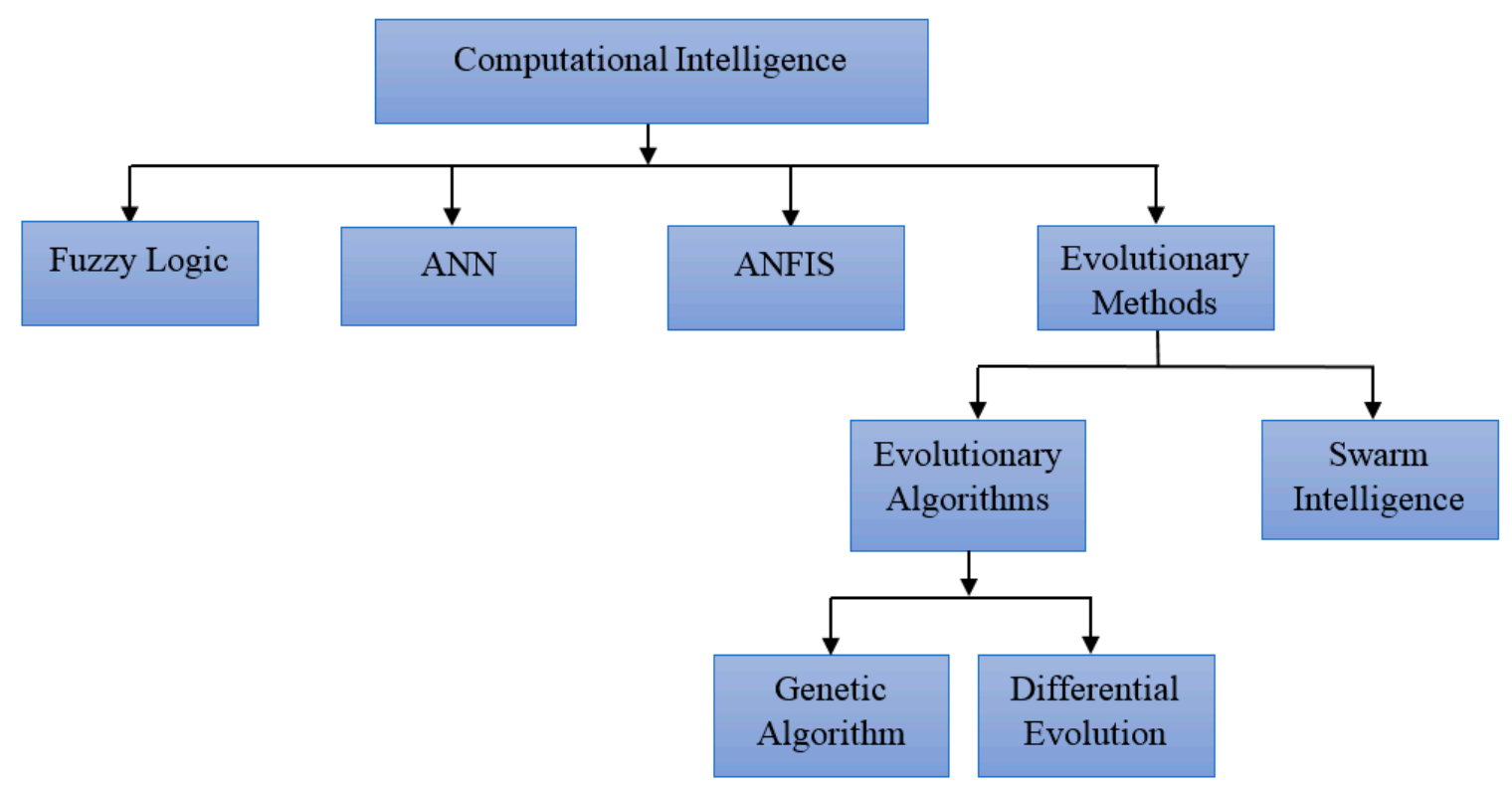

Figure 2. Computational intelligence (CI)-based optimization techniques.

$\mathrm{CI}$ is a broader field of study and its applications can be found in several modern-day scientific and engineering problems, however, this study only focuses on the CI techniques that are explored for the power quality and dynamic response enhancement of ac MGs only. The basic idea is to optimize different control parameters such as PI regulator gains [9,10], droop coefficients [11,12], maximum power point tracking (MPPT) of wind turbines and solar PV modules $[13,14]$ and wind turbine pitch angle $[15,16]$ that consequently lead to the accomplishment of the mentioned MG control objectives.

Before discussing the applications of the CI-based optimization methods in MG controls, it is important to understand the basics of the optimization process in general. Optimization is a process of finding the most suitable values of the variables that provide the maximized or minimized value of a given fitness function under pre-defined constraints [17]. Two of the most important performance evaluating metrics of an optimization process are convergence rate and solution quality $[18,19]$. These parameters decide the efficiency of the algorithm in obtaining the optimal solution for any optimization process $[18,20]$. The convergence rate indicates the speed at which the fitness function is minimized or maximized by an optimization algorithm while the solution quality provides the information about the magnitude of the ultimate maximum or minimum value of the fitness function at the end of the optimization process $[21,22]$. It is worthwhile to mention here that, due to space and scope constraints, this study excludes swarm intelligence-based optimization methods as it is very hard to justify with all such optimization techniques in the current study. Furthermore, the current study only considers the applications of the mentioned CI-based optimization methods for mitigating power quality issues, MPPT and regulation of system frequency, voltage and power flow in ac MG systems. It is evident from the surveyed literature that each of the quoted CI techniques has been studied extensively and found to be beneficial in mitigating the MG stability, power quality and transient response issues. Nevertheless, despite of the immense applicability and benefits of these CI techniques in ac MGs as quoted in several 
research works, there is not a single publication available that can provide a detailed summary and insights about this important subject. Unlike the CI-based MG applications, the conventional MG control techniques are fairly studied and their extensive reviews are produced in [23-25].

As such, this study attempts to fill this knowledge gap by compiling and reviewing all the major publications on CI-based MG control architectures for the power quality and dynamic response enhancement of the ac MGs. Before discussing the applications of the CI techniques in the mentioned field, their basic working mechanism along with merits and demerits are discussed in order to provide a broader understanding of that CI methods and their application in the studied subject. Finally, the logical conclusions are drawn, and the suggestions are provided so that the research in the current field may be extended with novel ideas and innovations.

To accomplish the stated goals of the study, Section 2 of this paper provide details about the methodology adopted for the selection of the articles for review. The working mechanism of ANN, FL, ANFIS, and GA along with the merits and demerits and their application in ac MGs are discussed in detail in Section 3, Section 4, Section 5, and Section 6, respectively. Finally, the conclusion and the recommendations related to the CI-based optimal MG controls are provided in Section 7 of the article.

\section{Review Methodology and Scope}

In this section, the methodology adopted for selecting the published articles on the studied subject is discussed along with the scope of the review. Initially, the articles for review were chosen from three of the key online sources i.e., Web of Science [26], Google Scholar [27], and Scopus [28] by using searching keywords such as computational intelligence-based optimization in ac microgrids, optimized frequency and voltage control of autonomous ac microgrid, optimized dynamic response of ac microgrid, optimal control of distributed generating units and optimal power sharing control in grid-tied MG. Once the articles were extracted from their online sources, a classification-based method was adopted to select the most relevant articles based on the subject relevance, journal quartile, impact factor, and Scopus ranking. Owing to the limited space, only 42 of the most relevant articles were chosen to explore four of the well-known CI-based methods, namely, FL, ANN, ANFIS and GA for their application in ac MG controls. To properly execute the current study and to achieve its aims and objectives effectively, an outline of the article contents was prepared. All the sections have been arranged in such a way that the adjacent sections must have some coherence and relation to each other and the core aim of the study. Table 1 shows the classification of selected articles based on $\mathrm{CI}$ optimization methods and the major focus of study i.e., dynamic response and power quality improvement.

Table 1. Classification of selected studies.

\begin{tabular}{cccc}
\hline CI-Based Optimization Methods & \multicolumn{3}{c}{ Published Articles } \\
\hline & MPPT & Voltage, Frequency and Power Regulation & Reactive Power Compensation and Power Quality \\
\hline ANN & {$[13,29]$} & {$[30,31]$} & {$[32,33]$} \\
FL & {$[34-36]$} & {$[10,15,16,37-45]$} & {$[46-51]$} \\
ANFIS & {$[14,52-56]$} & {$[12,57]$} & {$[58,59]$} \\
GA & {$[60,61]$} & {$[9,62-65]$} & {$[66,67]$} \\
\hline
\end{tabular}

As stated in the previous section of this paper, it is almost impossible to fairly cover all the CI-based optimization methods due to the space constraints, therefore, only a few of the very important and basic $\mathrm{CI}$ techniques were selected for the review and are presented in the subsequent sections.

\section{Artificial Neural Networks}

ANN is extensively accepted as a technology with great potential to solve most of the complicated and ill-defined problems. ANNs are capable of learning from examples, tackling non-linear problems, and handling incomplete and noisy data. Furthermore, ANN can do generalization and prediction at rapid speed after proper training procedures. Due to its effective learning ability, it has been 
successfully applied in several scientific applications like forecasting, signal processing, control, medicine, power systems, pattern recognition, manufacturing, robotics, optimization, psychological and social sciences [68]. ANN is an interconnection of artificial neurons (nodes) that mimic the functionality of a human brain. Mainly, it contains three layers, i.e., input, hidden, and output. A generalized flowchart of ANN modeling and a simple structure of ANN tailored for frequency and voltage control of an islanded MG is depicted in Figures 3 and 4, respectively.

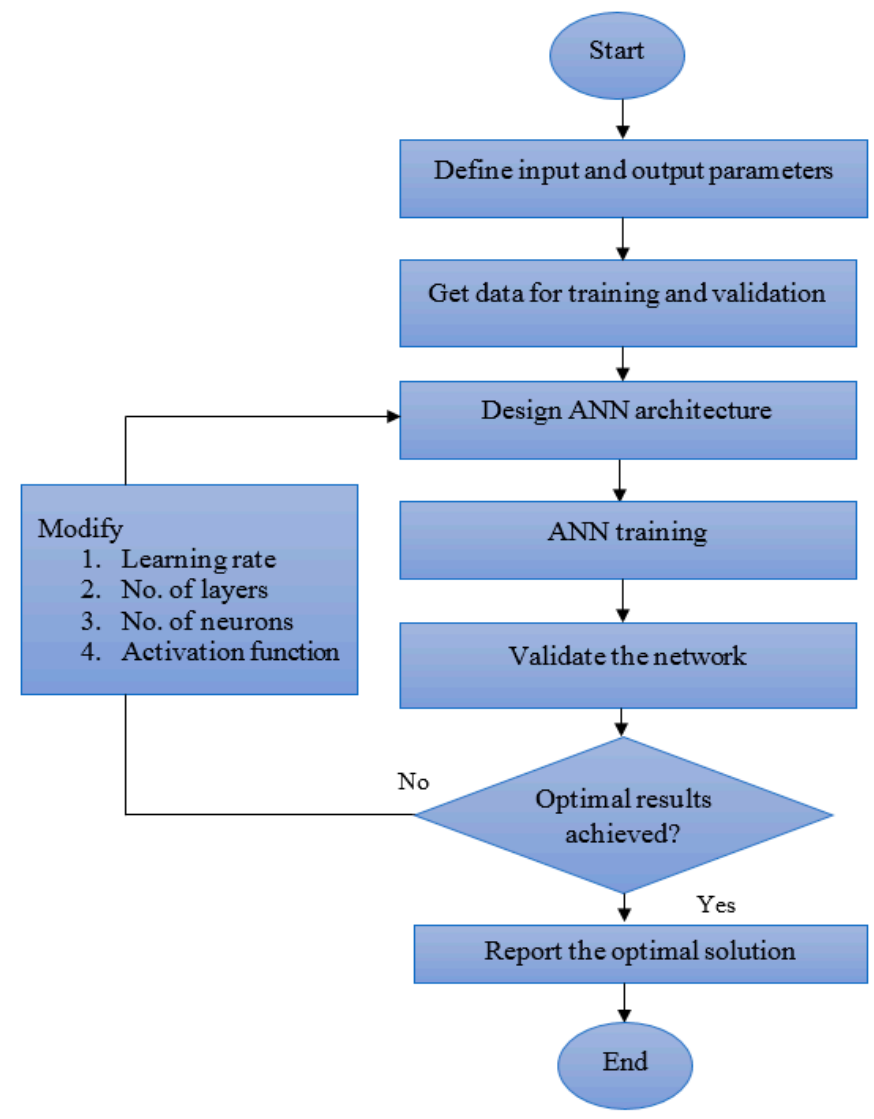

Figure 3. A generalized artificial neural network (ANN) modeling flowchart for optimization.

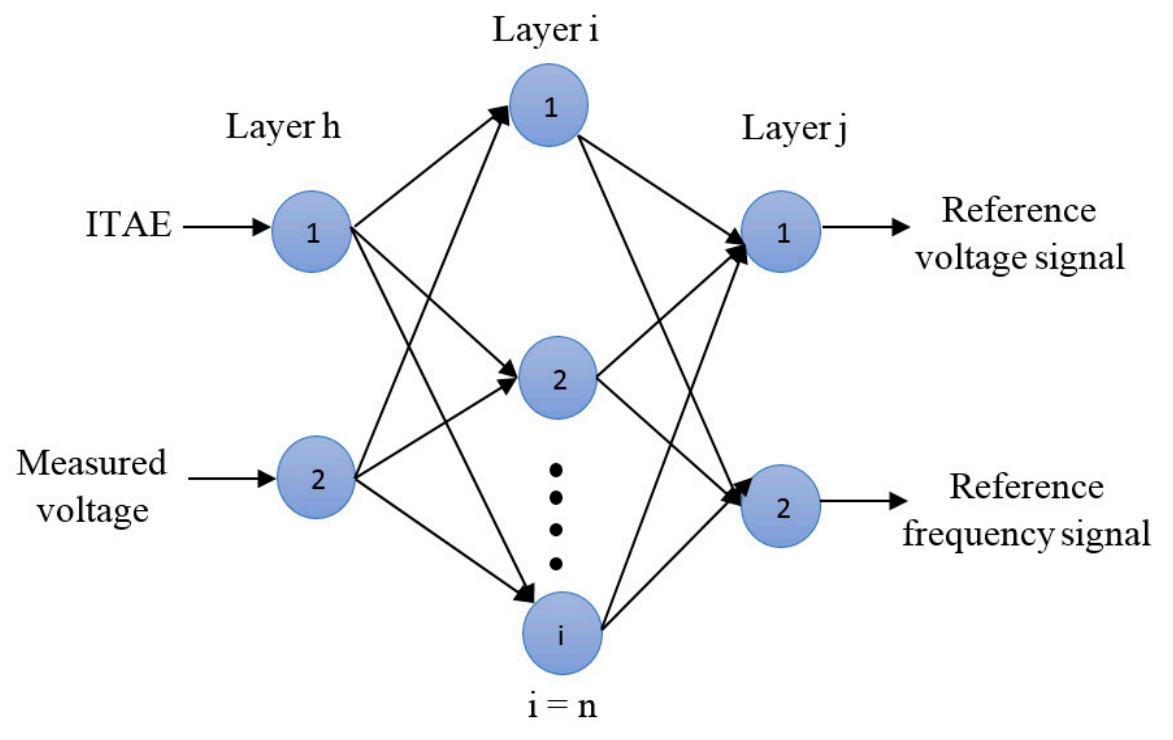

Figure 4. A typical ANN structure for voltage and frequency control of islanded MG. 
The main feature of an ANN is its ability to solve a complex problem very efficiently since it can handle the data parallelly. Furthermore, the ability of ANNs to learn from examples spontaneously, reason over fuzzy data, and provide quick and adequate responses to new information have attracted the interest of several researchers to solve different optimization problems of the power engineering field through this CI technique [69].

\subsection{Applications of ANN in ac MG Controls}

ANN has been widely used in dynamic response and power quality improvement of ac MGs. A few of the most relevant ANN studies in the field of MG controls are selected for the review in this research work and are discussed in subsequent subsections.

\subsubsection{ANN-Based MPPT}

A general regression neural network (GRNN) algorithm was used to achieve MPPT of solar PV in a grid-tied wind-PV power system by Hong et al. [13]. To attain a fast and stable performance, an intelligent radial basis function network-sliding mode controller was implemented along with the GRNN-based MPPT controller. Rezvani et al. attempted to improve the dynamic response of a wind-solar-based grid-connected MG system by using a GA-trained ANN (GA-ANN) for MPPT control of solar PV and FL-based pitch angle control for the wind turbine [29]. The proposed GA-ANN-based controller ensured the fast-tracking and reduced fluctuations around the maximum power point in solar PV under different insolation conditions while the FL-based pitch angle controller regulated the wind output power under variable wind speed.

\subsubsection{ANN-Based Reactive Power Compensation and Power Quality Enhancement}

In addition to MPPT control, the ANN has also been used for the reactive power regulation and power quality enhancement of ac MGs. Bansal et al. adopted the ANN-based approach for tuning PI controller-based static VAR compensator (SVC) in an autonomous hybrid system [32]. The role of the ANN-tuned SVC controller was to regulate the reactive power of the ac MG system. The performance index was studied for a $1 \%$ step change in reactive load demand, and it was found that the deviation in both firing angle and system voltage vanishes in $0.2 \mathrm{~s}$ of simulation. The lead author R.C Bansal has extended the previous work by simulating the model for different load voltage characteristics of the wind-diesel system in reference [33]. It was found that the voltage and current oscillations vanish in $0.01 \mathrm{~s}$ when SVC supplies the reactive power required by the load or induction generator.

Baghaee et al. added the radial basis function neural networks (RBFNNs)-based complementary control loop to the conventional droop control scheme for regulating the reactive power and improving the power-sharing capability of DGs in an ac MG system [31]. The inclusion of the RBFNNs in droop control ensured the accurate and faster power calculations for improving the MG stability and power-sharing ratio. Li et al. proposed an ANN-based vector control method to avoid the demerits of the traditional vector control methods in their applicability to dynamic systems for grid-connected converters [30]. The NNs were trained by using the backpropagation method in conjunction with a dynamic programming algorithm.

Although the ANNs are robust in solving nonlinear problems and are easy to train, there are certain disadvantages related to ANN which limit their extensive usage in modern MG control architectures. For example, the ANN must be trained for each problem separately. Moreover, multiple tests must be performed to define adequate algorithm architecture. Lastly, its training might be long and time-consuming as the training requires large volumes of data [70].

\section{Fuzzy Logic}

Fuzzy logic control (FLC) systems utilize a mathematical calculus to decode the subjective knowledge of humans for the real processes [71]. The FL theory was introduced by Lotfi Zadeh in 1965 [72]. The behavior of such systems is defined through a set of fuzzy-based rules that uses linguistics 
variables with symbolic terms to formulate the solution of a given problem [73]. A generalized FLC structure is shown in Figure 5. It contains three stages of processing, i.e., fuzzification, rules inferences, and de-fuzzification. The rule table block stores the fuzzy rules and the calculations are performed in the rule's interference unit.

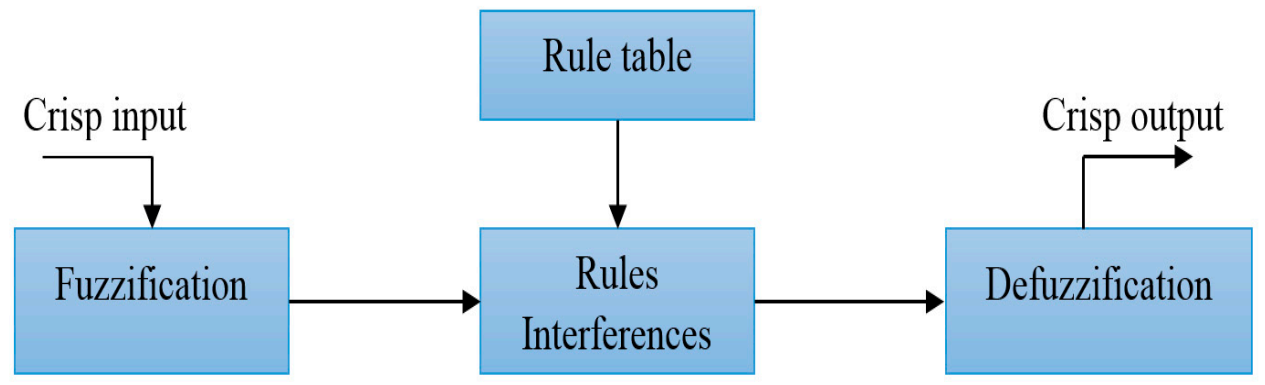

Figure 5. The basic structure of fuzzy logic [74].

Furthermore, for a clear understanding of the applicability of fuzzy logic in MGs, a typical example of FLC is shown in Figure 6. In this case, fuzzy logic is used to select the optimal values of generalized droop coefficients $(R$ and $X)$ to regulate the voltage and frequency of an ac MG. For obtaining the optimal values of the mentioned coefficients, a set of 36 fuzzy rules, which are very well defined and explained in reference [11], is utilized to map four input parameters, i.e., $\Delta f, \Delta v, \Delta P$ and $\Delta Q$ (deviation in frequency, voltage, active power and reactive power, respectively), and two output parameters, $R$ and $X$.

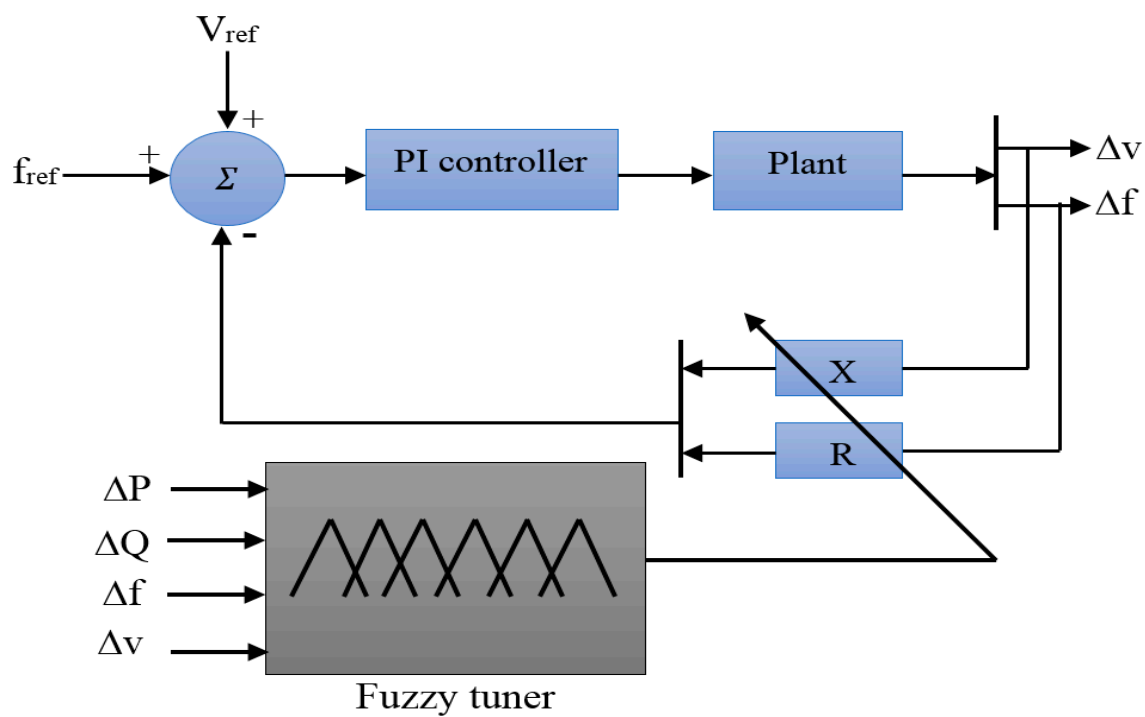

Figure 6. Optimal selection of droop coefficient using fuzzy logic [11].

The FLC has been extensively applied to deal with the power quality issues in the power system due to its simplicity, ease in interpreting the results, approximate reasoning, and provision to extend its basic knowledge by adding new rules. Furthermore, FLC is also recognized and found effective in handling problems with non-linearity. The FLC applications in power quality enhancement of MGs are extensively reported in the literature, out of which few prominent studies are reviewed and briefly discussed in the current study as under.

\subsection{Applications of FL in MG Controls}

A few of the very important applications of MG controls in the context of current research work are discussed in detail. 


\subsubsection{FL-Based MPPT}

Alajmi et al. have carried out an experimental setup for a conventional FLC-based hill-climbing MPPT controller in an islanded MG under changing weather conditions [34]. The objective of fuzzifying the rules of the hill-climbing search method was to avoid the sluggish MPPT convergence to the optimum operating point and to minimize the power loss at the steady-state condition. The results presented the efficacy of the proposed control method over the previous research works based on the dynamic response indicators, tracking accuracy, number of fuzzy rules, execution speed, and practical validation. Authors in reference [36] proposed FLC for MPPT control of solar PV in an ac MG. The mentioned study aimed to increase PV system performance during various partially shaded circumstances. Both the simulated and experimental results were analyzed to validate the effectiveness of the developed controller. Another significant research work pertaining to FLC-based MPPT was carried out by Patcharaprakiti et al. where they proposed an adaptive FLC for achieving MPPT of a grid-tied solar PV system [35]. The developed algorithm could suitably adjust the fuzzy parameters for the appropriate transient response of the considered system. Results showed that the adaptive FLC-based MPPT possesses the capability of extracting a greater amount of power than the conventional MPPT controller with a higher power factor and lower harmonics.

\subsubsection{FL-Based Reactive Power Control and Power Quality Enhancement of MGs}

Another important application of the FLC-based MG control architectures lies in the power quality improvement of ac MGs. In this context, Benachaiba et al. utilized the FLC to tune parameters of unified power quality conditioner (UPQC) for improving the voltage profile of an ac MG system [46]. The effectiveness of the proposed controller and its performance was compared with the conventional PI controller in mitigating voltage sag and unbalancing. The FLC-based UPQC reduced the total harmonic distortion (THD) in source current down to $2.11 \%$ as compared to the conventional PI controller where the same value was recorded as $2.23 \%$. A tariff-based FLC was developed to compensate the reactive power and current harmonics in an ac MG [47]. The controller rules were set in such a way that the MG with the lowest tariff and THD was integrated with the utility grid. Furthermore, along with the tariff management, the controller reduced the THD up to $3.64 \%$. In another study, the authors designed an FLC-based dynamic voltage restorer (DVR) for eliminating the voltage sags and swells during overloading, underloading, and fault conditions in the grid-connected wind farms [48]. Solar PV was used in the control structure for providing an alternative energy source to the DVR. FLC-based DVR has also been proposed by Ramasamy et al. To minimize the voltage sags, swells, and outages in a single-phase distribution system [49]. In the mentioned research work, the DVR along with the PV module with both high and low boost power converters was used as a DC voltage source for mitigating the voltage outages, sags, and swells. In reference [50], the authors designed a fuzzy-based PI controller for inverter control in a grid-tied MG. The gains of the PI controller were tuned by the FLC to achieve the required operating point of the MG system. Both experimental and simulated analyses were made. In order to validate the effectiveness of the proposed method, its outcomes were compared with the identical system equipped with the conventional PI controller. The THD for the proposed controller was reported as $3.85 \%$ in simulation and $4.4 \%$ in experimental results. Most recently, Mukhopadhyay et al. proposed a fuzzy PSO-PI-based controller for controlling static synchronous compensator (STATCOM) for compensating the voltage sags in a grid-tied wind power system [51]. The authors compared the performance of three different CI algorithms, i.e., PSO-PI, fuzzy-PI, and fuzzy PSO-PI for five different cases, namely; wind speed variation along with grid voltage dip, line-to-line fault, double-line-to-ground fault, single-line-to-ground fault and a huge abrupt load change. 


\subsubsection{FL-Based MGs Dynamic Response Enhancement}

FLC has also been extensively applied to regulate the MG parameters such as voltage, frequency, and power with great accuracy and dynamic response. Marzband et al. developed an FLC to improve the dynamic performance of an islanded wind-diesel system [37]. The system frequency, voltage, wind turbine output power, rotor speed, and torque were regulated and compared with that of the PID controller to authenticate the usefulness of the proposed method. The outcomes of the study proved that the proposed controller outperforms the conventional PID controller in controlling the mentioned variables with reduced settling time and overshoot. In another study, Rashed et al. utilized the FLC for the diesel engine speed control in a PV-diesel based islanded MG [38]. The MG system performance was studied under various operating conditions like varying solar insolation, abrupt load insertion, and changing wind generator torque. The major benefits of the reported control scheme include the elimination of the auto voltage regulator in a diesel generator, minimized power loss in diesel generator field circuit, and optimal dynamic response of voltage control. Kamel et al. proposed an FL-based pitch angle controller for achieving smooth power from a wind turbine [15]. The key objective was to decrease the variations in system voltage, frequency, active and reactive power during islanding occurrence. The proposed controller displayed a better response for the mentioned variations as compared to the traditional PI controller-based control scheme. In another study, the same authors as that of [15] extended their previous research work and proposed an FL-based pitch angle controller along with an energy storage ultra-capacitor to minimize the fluctuations from the output wind turbine power in an autonomous MG network [16]. The performance of the designed controller was evaluated for wind speed greater than its rated value. The controller provided an excellent response in smoothing the frequency, voltage, and power profile of the studied MG system. Li et al. presented a self-organizing fuzzy PI regulator-based MG control strategy to minimize the frequency and power fluctuations during islanded and grid-tied operation of the MG [40]. The authors validated the superior performance of their proposed control scheme by comparing its dynamic response with that of the traditional PI regulator-based control scheme under identical operating conditions. In another study, Diaz et al. proposed a decentralized gain-scheduling control strategy based on FLC [39]. The aim of this research work was to balance the stored energy among various distributed energy storage units and to minimize the voltage deviations in an islanded MG. Ngamroo et al. presented a fuzzy-based coordinated control of aqua electrolyzer and fuel cell to suppress the power fluctuations in an ac MG [10]. To avoid the possibility of the suboptimal response of the system, bee colony optimization (BCO) was used to optimally select the FLPID parameters. The outcomes of the research proved that the presented controller provides a smaller power deviation than that of the conventional FLPID controller under similar MG operating conditions. In reference [41] the authors proposed an FL-based control method for reducing the power fluctuations in a wind-PV based hybrid power system. The power profile of the mentioned power system was studied under two different cases; (i) when the state of charge (SOC) of the battery was $95 \%$ and (ii) when the SOC was reduced to $5 \%$. The major aim of the study was to control the SOC of the battery to smoothen the power output of the considered hybrid power system. Chamorro et al. presented a control strategy for smoothing the active and reactive power flow in both autonomous and grid-connected modes of ac MG [42]. In the presented control strategy the local controllers were made responsible for deciding the power and voltage set-points in conjunction with a central command. Senjyu et al. proposed an FLC for leveling the power and frequency fluctuations caused by varying solar insolation in a PV-based power system [43]. The output PV power during the large frequency deviations was smoothed using the proposed controller and also increased the generated PV power up to maximum available power during low-frequency deviations. An FLC-based PI regulator was presented to control the ac MG's voltage and frequency in [44]. As compared to the traditional PI regulator-based control structure, the overshoot and settling time was reduced and brought to $4.64 \%$ and $0.0022 \mathrm{~s}$, respectively. Salhi et al. [45] developed a fuzzy controller for regulating the frequency of the micro-hydro power plant at different loading conditions. The PI parameters were dynamically selected by a fuzzy controller to optimize the system's dynamic response, however, 
in case of overloading, the fuzzy controller disconnects a user load arbitrarily to keep the frequency at a constant value.

Although the FL has been effectively employed in solving several MG optimization problems in the past due to its simplicity and approximate reasoning, it has some disadvantages which limit its use in modern MG controls. For example, the performance of an FLC is a function of its control rules and membership functions. It is very difficult to tune these parameters optimally according to the process in which it is employed. Hence these controllers do not possess an effective learning capability. This makes the FLC an inconvenient controller for the application of MG power quality enhancement as the nature of DGs and loads are completely unpredictable and dynamic. The solution to this problem is to use another $\mathrm{CI}$ algorithm to tune the FLC parameters according to the system dynamics. For example, authors used GA in [75], online PSO [76], BCO [77] and chaotic PSO [78] to tune FLC in MG controls. Furthermore, the Adaptive neuro-fuzzy inference system is also one of the most efficient solutions to the stated problems, as discussed in the subsequent section [79].

\section{Adaptive-Neuro Fuzzy Inference System}

The review of ANNs in the previous section of the paper revealed that the ANNs are mathematical models that employ computational neurons arranged in layers and are linked with one another by weight factors. The main features of ANNs include an adaptive and nonlinear structure, generalization skills, independence from system design parameters, efficient learning, and parallel data handling capabilities. However, there are some demerits associated with ANNs like lacking rules for defining the structure, network instruction problems, and a black box nature [58]. On the other side, FL is a technique generally used in microprocessor-based control systems because it does not need a precise system model and is insensitive to the parameter and operating point variations. However, its major disadvantage is that its membership functions and rule basis are generally selected by the "trial and error" method which is a time-consuming and error-prone process [58]. However, the advantages of these two robust control CI techniques can be merged to form neuro-fuzzy systems.

The neuro-fuzzy systems utilize the learning and parallel data processing capability of ANN and rule inference capability of FL. One of the most effective neuro-fuzzy systems is named ANFIS, which was developed in 1993 by Jang [80]. ANFIS utilizes the ANN learning rules for tuning fuzzy parameters based on the data available for training. Its major characteristics include (i) easy implementation, (ii) rapid and accurate learning, (iii) strong generalization skills, (iv) easy understanding of the algorithm due to fuzzy rules, and (v) easiness in incorporating both numeric knowledge and linguistics for problem-solving [81]. Atmaca, H. et al. compared the performance of fuzzy inference and ANN with ANFIS-based systems in acquiring fuel consumption data [82]. The results show that the learning period of ANFIS is quite short compared to the ANN case. In other words, ANFIS reaches the steady-state value quicker than ANN. A typical structure of an ANFIS is depicted in Figure 7.

In this Figure, circles denote the fixed nodes while the squares signify the adaptive nodes. It shows a feed-forward multilayered network in which every layer has a specified function on the input signals. In the example shown in Figure 7, ANN has five layers with two inputs $(x, y)$ and one output $(\mathrm{z})$. In the starting layer, the nodes $\left(\mathrm{A}_{\mathrm{i}}, \mathrm{B}_{\mathrm{i}}\right)$ hold the membership functions assigned to each of the two inputs. In the second layer, the system recognizes two rules i.e., rule 1: $x=A_{2}$ and $y=B_{1}$; rule 2: $x=A_{2}$ and $y=B_{2}$. The calculation of normalized firing strength of each rule $\left(W_{1}, W_{2}\right)$ is performed by the third layer. The fourth layer contains the linear functions of the input signals $\left(f_{1}=p_{1} x+q_{1} y+r_{1} ; f_{2}=p_{2} x+q_{2} y+r_{2}\right)$ and the normalized firing strength of each rule estimated in the previous layer. Finally, the overall output of the system $(\mathrm{z})$ is calculated in the last layer by summing all the incoming signals.

Since its very formation, the ANFIS has been used extensively in MG control architectures as an effective optimization tool. A few of the very important articles on ANFIS based MG controls are discussed in the current study. 
Layer 1

Layer 4

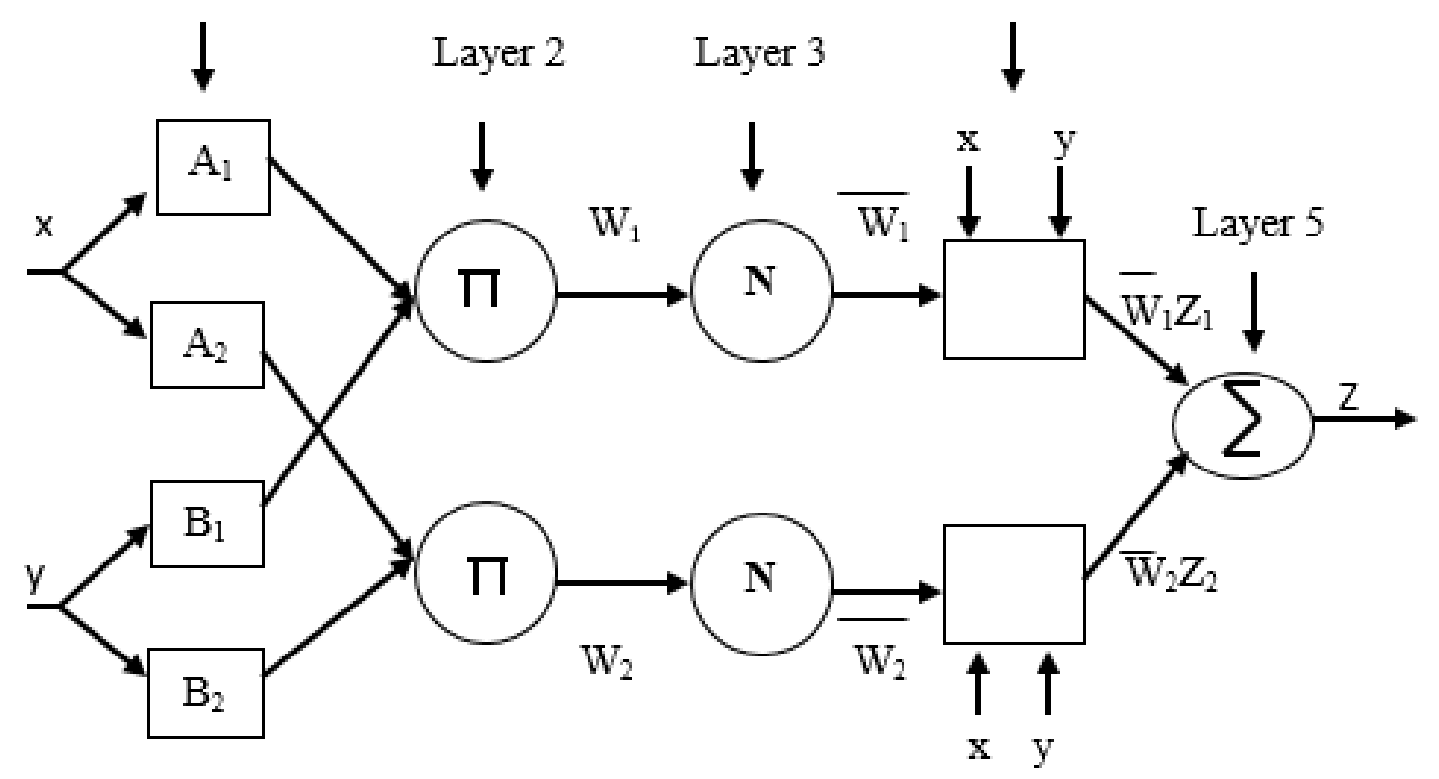

Figure 7. The typical structure of an adaptive neuro-fuzzy inference system (ANFIS) $[58,80]$.

\subsection{Applications of ANFIS in MG Controls}

A few of the significant studies related to ANFIS-based MG controls were selected for the current study and are discussed in detail for a better understanding of the current subject.

\subsubsection{ANFIS-Based MPPT}

Izadbakhsh developed an ANFIS-based MPPT controller for solar PV and pitch angle regulators for the wind turbine generator in a grid-tied MG system [52]. A set of 360 data points from solar PV irradiance and the temperature was collected by using GA to train the ANFIS. The proposed controller increases the convergence speed for attaining the maximum power point and hence decreases the oscillations from the output PV power. Vafaei et al. presented a GA-based ANFIS (GA-ANFIS) method to attain the maximum power from the solar PV system [53]. In the mentioned study, the reference voltage values were optimized by GA which was then used for training the ANFIS model. The ANFIS output was compared with the reference values to calculate the accuracy of the presented model. The proposed controller reduced the error between the measured and the reference voltage to less than $2 \%$. Kamel et al. also presented a neuro-fuzzy based controller for obtaining MPPT of the solar PVs in an ac MG system [54]. A MATLAB/Simulink model was designed to evaluate the wind-solar-based MG's dynamic response during and after the islanding process. Furthermore, the pitch angle controller was designed to smooth the power output of the wind turbine generator. In reference [55] of the current study, the authors proposed an adaptive wavelet-based neuro-fuzzy controller for solar PV MPPT. The presented controller combines the localization property of wavelet, the learning capability of NN, and the reasoning capability of FL to overcome the fluctuation in MPPT controller output. By applying the proposed control scheme, the PV achieved an efficiency of $96.81 \%$ which was recorded as $83.66 \%$ in the case of FLC. Chettibi and Mellit proposed an online-trained Elman NN-based control scheme for MPPT of a solar PV source in a grid-connected hybrid power generation system [56]. To optimally regulate the flow of active and reactive powers, ANFIS was used to tune PI controller gains in a virtual flux-oriented controller (VFOC). In another study, the ANFIS controller was proposed for tracking MPPT of solar PV and FL was utilized for wind turbine pitch angle control in a grid-connected wind-PV MG system [14]. The focus of the research work was to smooth the power output from a wind turbine generator and solar PV under different operating conditions. 


\subsubsection{ANFIS-Based Power Quality Enhancement of MGs}

ANFIS has also been explored for the enhancement of ac MG power quality. Garcia et al. [58] proposed an ANFIS-based controller for controlling a three-phase inverter in a grid-connected MG to control the power-sharing ratio and to enhance the power quality at the same time. Furthermore, as compared to the conventional PI regulator-based control scheme, the presented controller reduced the THD to $7.15 \%$ from $7.71 \%$ in transient and $4.11 \%$ from $4.29 \%$ in a steady-state condition. In another study, the authors proposed a neuro-fuzzy based UPQC controller to reduce voltage unbalances and harmonics in a grid-tied MG system [59]. With the application of an ANFIS-based controller, the THD of the grid current was reduced to $3.34 \%$ as compared to $8.93 \%$ in the case of the conventional PI controller.

\subsubsection{ANFIS-Based MG Dynamic Response Enhancement}

Finally, few applications of the ANFIS in the regulation of MG system parameters are reviewed in order to provide an outlook of the dynamic response enhancement of ac MGs using an ANFIS application. Shokoohi et al. [12] proposed a neuro-fuzzy-based droop control strategy to minimize the frequency and voltage oscillations in an islanded MG. ANFIS was used to optimize the droop coefficients to optimally set the voltage and frequency set-points under varying load conditions. The proposed control strategy is used to maintain the MG stability under severe load changes regardless of the MG structure. Authors in reference [57] developed a novel online PI controller tuning algorithm for an ac MG system. The proposed algorithm, named by authors as the critic-based self-tuning PI (CSPI), consists of a neuro-dynamic programming concept in conjunction with a fuzzy critic and was used to control the power output of the VSCs in MG systems. The proposed controller reduces the active power overshoot and brings it to $10.05 \mathrm{~kW}$, with a mean absolute error of $0.16 \%$ and THD of 0.054 in the transient period as compared to that of the PI controller where the active power overshoot, mean absolute error and the THD were recorded as $15.25 \mathrm{~kW}, 0.56 \%$ and 0.108 , respectively.

Although ANFIS networks allow a suitable integration with other control methods and present a better-structured data representation, updating and training the ANFIS parameters is one of the tough tasks due to its complex gradient calculation-based training process. Furthermore, the ANFIS can also get trapped into the local minimum due to the applicability of chain rule [83]. To solve these problems, different CI methods such as GA [84], PSO [85], adaptive PSO [86] and ABC [87] are utilized to update the ANFIS parameters instead of the conventional gradient method in modern MG control architectures.

\section{Genetic Algorithm}

GA is considered as an intelligent metaheuristic-based optimization technique that uses a probabilistic, guided, multipoint, and random search mechanism to solve the optimization problems [88]. It is a search algorithm based on the mechanism of population genetics and natural selection. GA was proposed by Holland in 1992 [89] and was further advanced by Goldberg [90] and others. GA has been widely used to optimize the nonlinear systems such as inverter-based MGs. This is the key reason that GA has been extensively used in MG controls as a strong optimization technique to solve the various optimization problems as reported in the literature. In GA, an optimization function is encoded as character strings or arrays of bits to characterize the chromosomes. These strings are then manipulated and tested for their fitness values to solve the concerned problem. A general flowchart of GA is depicted in Figure 8. 


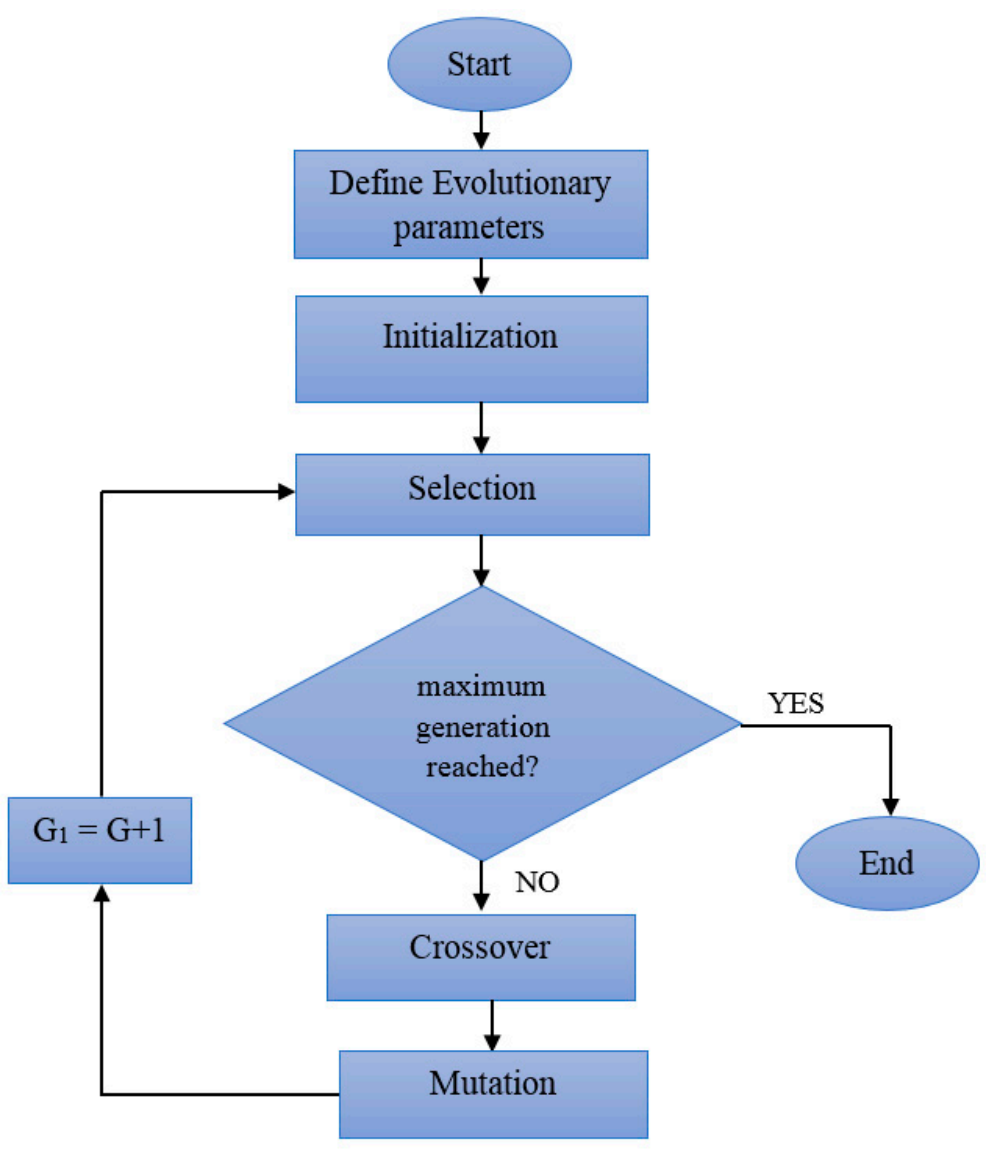

Figure 8. Flowchart for the working mechanism of a genetic algorithm (GA) [91].

In the "Initialization" block, each chromosome is assigned with some random values in the search space. Next, these chromosomes are assessed based on their fitness values. In the "Selection" block, a set of predefined fit chromosomes is selected, while in the "Crossover" operation the new chromosomes are traced to create hybrid individuals that have a greater fitness value as compared to their predecessors. Finally, to avoid the local minima entrapment, a "Mutation" operator is used at the last stage of the optimization process. All these steps are repeated in the same order until the desired convergence is achieved [92].

\subsection{Applications of GA in Ac MG Controls}

Due to the stochastic nature and ability to deal with complex optimization problems, the GA has been utilized several times to solve MGs optimization problems. A few of the major applications of the GA in MG controls are discussed in the following subsections.

\subsubsection{GA-Based MPPT}

Razavi et al. optimized the droop coefficients and PI gains $\left(K_{p}\right.$ and $\left.K_{i}\right)$ by employing GA to minimize the frequency variations in an ac MG system [62]. The major aim of the control strategy was to enhance the transient response (overshoot and settling time) of the system by using optimal droop coefficients and other control parameters. In another study, Dc Das et al. proposed a GA-based frequency controller to regulate the frequency of a hybrid solar thermal-diesel-wind energy generation system [9]. GA was used to optimize the gains of the conventional PI controller in the proposed hybrid MG system. The presented controller's performance was compared with that of the conventional controllers on a basis of different transient response indicators like settling time, overshoot, and oscillations, which 
proved the superiority of the proposed controller under identical operating conditions. However, a large settling time ( $3.5 \mathrm{~s}$ ) was observed after a step load change.

\subsubsection{GA for Dynamic Response Enhancement of MGs}

The GA can also be used to train other algorithms like ANN, FL, and PSO to enhance their searching capabilities. For example, GA was used to optimize the FLC parameters in [63]. It was used for the selection of optimal control rules and membership functions for the FLC. In reference [64], GA was used to tune and optimize the membership function parameters of FLC to obtain the optimal performance of a wind-diesel-based hybrid MG system. The efficacy of the presented controller was validated by simulating it on the standard IEEE nine-bus, three-generators test system. Furthermore, the controller was simulated under normal and faulty conditions to authenticate its robustness. It was shown that the proposed controller-based wind-diesel MG system provides a frequency deviation of only $0.4 \mathrm{~Hz}$ at a $25 \%$ increment in the wind power penetration. Wies et al. used GA for tuning the PID regulator to control the system voltage and frequency in an islanded wind-diesel mini-grid [65]. The proposed control strategy was tested under varying wind speed and load conditions for the voltage and frequency control. A mean load frequency and bus voltage deviation of 0.021 mean $(\mathrm{Hz})$ and 0.782 mean $\left(\mathrm{V}_{\mathrm{rms}}\right)$, respectively, was observed with a GA-based PI controller at a mean wind speed of $6.6 \mathrm{~m} / \mathrm{s}$, while the same was 0.185 mean $(\mathrm{Hz})$ and 5.52 mean $\left(\mathrm{V}_{\mathrm{rms}}\right)$ at identical conditions with manual PI parameter selection.

It is evident from the above review that the GA stood as an appropriate solution for the optimization problems of nonlinear systems such as inverter-based MGs. However, GA suffers from a low convergence rate due to an unguided mutation process; thus, it finds difficulty in running with dynamic data sets [20]. This problem can be avoided by combining it with some other algorithms which perform guided search like differential evolution. Furthermore, unlike the swarm intelligence (SI)-based optimization methods that possess memory, in GA the information contained by an individual is lost if that particular individual is not selected. In addition, it can be trapped into local solutions easily [5], however, this disadvantage of GA can also be avoided by using it in conjunction with a global optimization method that can escape from any local point, such as a simulated annealing (SA) [93] or an SI-based optimization method like PSO [94,95].

Table 2 provides the summarized version of all the studied articles with significant information about the study such as the objective of the study, the CI method used, DG utilized, studied MG operating mode, and considered MG operating conditions.

Based on the facts presented in Table 2, it is evident that all the CI-based optimization algorithms possess the ability to solve MG's optimization problems effectively. However, each of the CI-based optimization methods discussed above suffers from a few limitations. For example, the ANN takes a longer time for its training and provides the optimal outcomes only for the known datasets. The FLC provides rapid convergence, however, it lacks an effective learning capability as it only responds to input data based on the predefined rules. Similarly, ANFIS possesses good adaptation and learning capability, however, it is characterized by higher computational complexity and sensitivity to the number of fuzzy rules. GA is a simple and effective optimization technique but suffers from problems like stagnation into local optimum and slow convergence. Hence, based on the stated merits and limitations and the MG control objectives, a suitable optimization technique may be adopted. The selection of an optimization technique also depends on various other factors such as the type of the optimization problem (single objective or multi-objective), the dimension of the problem (the greater the dimensions, the greater the time required to reach the optimal solution), fitness function complexity (optimization algorithms such as GA evaluate the fitness value repeatedly), the behavior of the objective function (generally multimodal functions are trapped in local solutions more easily), and the solution quality required. 
Table 2. CI-based techniques used for optimization in MG control schemes.

\begin{tabular}{|c|c|c|c|c|c|}
\hline Ref. & CI Optimization Technique & Research Objective & Utilized DGs & MG Operating Mode & Studied Conditions \\
\hline \multicolumn{6}{|c|}{ ANN } \\
\hline$[13]$ & GRNN & $\begin{array}{l}\text { Controlling boost converters to achieve the } \\
\text { maximum power point of a wind-PV system }\end{array}$ & Wind-PV & Grid-tied & Source and load changes \\
\hline [29] & ANN-GA & Active and reactive power quality improvement & Wind-PV & Grid-tied & Source and load changes \\
\hline$[30]$ & ANN & $\begin{array}{l}\text { To enhance the performance and stability of } \\
\text { inverter under disturbance }\end{array}$ & - & Grid-tied & $\begin{array}{l}\text { Load variation and power } \\
\text { converter switching }\end{array}$ \\
\hline [31] & RBFNNs & To improve the power-sharing among DGs & - & Both & Load changes and fault conditions \\
\hline [33] & ANN & The reactive power improvement & Wind-Diesel & Islanded & Load variations \\
\hline$[96]$ & ANN & Voltage and frequency regulation & - & Islanded & Sudden load changes \\
\hline \multicolumn{6}{|c|}{ FLC } \\
\hline [10] & BCO-FLC & To minimize the power fluctuations & Fuel cell and Electrolyzer & Islanded & Load changes \\
\hline [15] & FLC & Voltage and frequency control & Wind turbine & Islanded & Source changes \\
\hline [34] & FLC & Improvement in solar MPPT & Solar PV & Islanded & Source changes \\
\hline [35] & Adaptive FLC & To improve MPPT and harmonic reduction & Solar PV & Grid-tied & Source changes \\
\hline [36] & FLC & Improvement in solar MPPT & Solar PV & Islanded & Source changes \\
\hline [37] & FLC & Voltage and frequency regulation & Wind-Diesel & Islanded & Load changes \\
\hline [38] & FLC & Voltage and frequency regulation & PV-Diesel & Islanded & Load changes and overloading \\
\hline [39] & FLC & Voltage control & Wind and PV & Islanded & Load changes \\
\hline$[40]$ & FLC & Frequency and tie-line power control & $\begin{array}{l}\text { Micro-turbine, fuel cell and } \\
\text { electrolyzer }\end{array}$ & Both & Load changes and overloading \\
\hline$[41]$ & FLC & $\begin{array}{l}\text { To minimize the power fluctuations and to } \\
\text { control the state of charge of the battery }\end{array}$ & PV and Wind & Islanded & Source changes \\
\hline$[42]$ & FLC & The active and reactive power flow control & - & Both & Load change \\
\hline$[43]$ & FLC & $\begin{array}{l}\text { To minimize the power and frequency } \\
\text { fluctuations }\end{array}$ & Solar PV & Grid-tied & Source and load changes \\
\hline$[44]$ & FLC & Voltage and frequency regulation & PV and Fuel cell & Islanded & Source and load changes \\
\hline$[46]$ & FLC & To improve voltage profile & - & Islanded & Source changes \\
\hline$[47]$ & FLC & $\begin{array}{l}\text { The active power sharing and power quality } \\
\text { improvement }\end{array}$ & - & Grid-tied & Load changes \\
\hline$[48]$ & FLC & Voltage profile improvement & PV and Wind & Grid-tied & Fault conditions \\
\hline [49] & FLC & To minimize voltage sags, swells, and outages & Solar PV & Grid-tied & Load changes \\
\hline$[50]$ & FLC & Power-sharing and harmonic minimization & - & Grid-tied & Source changes \\
\hline [51] & PSO-FL & Frequency control & $\begin{array}{l}\text { Wind, Diesel, Electrolyzer, } \\
\text { Fuel cell and Solar thermal }\end{array}$ & Islanded & Source and load changes \\
\hline$[77]$ & BCO-FLC & To control active and reactive power & $\begin{array}{c}\text { PV, Wind, Fuel Cell and } \\
\text { Electrolyzer }\end{array}$ & Islanded & Severe Load changes \\
\hline
\end{tabular}


Table 2. Cont.

\begin{tabular}{|c|c|c|c|c|c|}
\hline Ref. & CI Optimization Technique & Research Objective & Utilized DGs & MG Operating Mode & Studied Conditions \\
\hline \multicolumn{6}{|c|}{ ANFIS } \\
\hline [12] & ANFIS & Voltage and frequency regulation & - & Islanded & Load changes \\
\hline [14] & ANFIS & To reduce fluctuations around MPPT & Solar PV and Wind & Grid-tied & Source changes \\
\hline [52] & ANFIS & Mitigation of fluctuations from MPPT & Wind, $\mathrm{PV}$, and Micro-turbine & Both & Source changes and fault condition \\
\hline [53] & ANFIS-GA & To reduce fluctuations around MPPT & Solar PV & Grid-tied & Source changes \\
\hline [54] & ANFIS & Voltage and frequency regulation & Wind and PV & Islanded & Source \\
\hline [55] & Neuro-Fuzzy Wavelet & Reducing fluctuations around MPPT & Solar PV & Islanded & Source changes \\
\hline [56] & Online trained Elman NN & Power flow control & PV and Fuel cell & Grid-tied & Source and load changes \\
\hline [57] & Fuzzy Critic & Voltage, frequency and power control & - & Both & Source changes \\
\hline [58] & ANFIS & To control the active and reactive power & Wind and PV & Grid-tied & Load changes \\
\hline [59] & ANFIS & Minimizing unbalancing in voltage & Solar PV & Both & Unbalanced and non-linear loading \\
\hline [79] & ANFIS & Power quality improvement & Wind and PV & Grid-tied & Source and load change \\
\hline [85] & PSO-ANFIS & To Reduce current harmonics & Solar PV & Islanded & Source changes \\
\hline \multicolumn{6}{|c|}{ GA } \\
\hline [9] & GA & Frequency control & $\begin{array}{l}\text { Solar thermal, PV Diesel, Fuel } \\
\text { cell, Electrolyzer and Wind }\end{array}$ & Islanded & Source and load changes \\
\hline$[62]$ & GA & Power-sharing and frequency control & - & Islanded & Load variations \\
\hline$[64]$ & GA-FL & $\begin{array}{l}\text { To minimize power, voltage and } \\
\text { frequency flickers }\end{array}$ & Wind turbine & Grid-tied & Source changes \\
\hline [97] & FL-GA & To Reduce current harmonics & Solar PV & Islanded & Source changes \\
\hline [98] & GA-ANFIS & To Reduce current harmonics & Fuel Cell & Islanded & Under transient state \\
\hline [99] & GA & Frequency regulation & Wind-Diesel & Islanded & Load and source changes \\
\hline$[100]$ & Epsilon Multi-objective GA & Frequency regulation & $\begin{array}{l}\text { Wind, PV, Fuel cell, Diesel, } \\
\text { Electrolyzer }\end{array}$ & Islanded & Load and source changes \\
\hline [101] & Non-dominated sorting GA & Frequency regulation & Wind-Diesel & Islanded & Load and source changes \\
\hline
\end{tabular}




\section{Conclusions}

This study has explored the basics of CI-based optimization approaches and their extensive applications in dynamic response and power quality improvement of ac MGs. This research work aims to provide a useful one-stop source of information to the researchers and experts working in the mentioned fields of research. A total of 42 of the most relevant articles were studied and reviewed to explore four of the most commonly employed CI optimization techniques, namely ANN, FL, ANFIS, and GA, along with their working mechanism, applications, merits, and demerits. It is established from the reviewed literature that the CI optimization-based controllers provide the most optimal MG operation and power quality as compared to the conventional MG controllers during DGs plug-in and severe load and source changes. Nevertheless, all CI optimization algorithms possess some limitations which need to be considered while employing them in any optimization problem. Therefore, it can be concluded that no optimization method is perfect for all the optimization problems since each method inherits certain demerits which limits their wide applicability. Moreover, according to the "No free lunch" theorem, no two optimization algorithms can be compared based on their ability to solve optimization problems in general. In other words, one optimization algorithm may perform better than others in a few optimization problems while the same is true for the second algorithm. Hence, the average performance of both algorithms in solving the optimization problems is essentially equivalent. Therefore, it is concluded that no optimization algorithm is universally better in solving all optimization problems. One of the modern trends is to hybridize two different optimization techniques in such a way that the strengths of one technique may be utilized to overcome the demerits associated with the other technique. In other words, both techniques can utilize their strong optimization capabilities to reach an optimal solution. For example, training of the ANFIS structure is a complex task that can be tackled by using a metaheuristic (GA, PSO) or evolutionary optimization technique. Similarly, the GA can be utilized to optimize the rules and membership functions of the fuzzy controller to enhance the performance of the FLC. However, since each algorithm has certain merits and limitations, it is not possible to declare any optimization algorithm as superior to others in all aspects.

Author Contributions: All the authors contributed significantly in making this article worth publishing in this esteemed journal. Further details are provided as follows; Conceptualization, T.A.J. and M.W.M.; Methodology, N.H.M.; Software, M.A.B.; Validation, I.K., N.N.H. and S.H.A.; Formal Analysis, M.M.R., T.A.J. and N.N.H.; Investigation, N.H.M.; Resources, I.K., N.N.H. and S.H.A.; Data Curation, M.A.B. and T.A.J.; Writing-Original Draft Preparation, T.A.J.; Writing-Review \& Editing, M.W.W.; Visualization, M.M.R. and N.N.H.; Supervision, M.W.M.; Project Administration, I.K. and M.W.M.; Funding Acquisition, N.N.H. and S.H.A. All authors have read and agreed to the published version of the manuscript.

Funding: This research received no external funding.

Conflicts of Interest: The authors declare no conflict of interest.

\section{References}

1. Lasseter, R.H. Microgrids. In Proceedings of the Power Engineering Society Winter Meeting, New York, NY, USA, 27-31 January 2002; IEEE: Piscataway, NJ, USA, 2002; pp. 305-308.

2. Nejabatkhah, F.; Li, Y.W. Overview of power management strategies of hybrid AC/DC microgrid. IEEE Trans. Power Electron. 2015, 30, 7072-7089. [CrossRef]

3. Zeng, Z.; Yang, H.; Zhao, R.; Cheng, C. Topologies and control strategies of multi-functional grid-connected inverters for power quality enhancement: A comprehensive review. Renew. Sustain. Energy Rev. 2013, 24, 223-270. [CrossRef]

4. Jumani, T.A.; Mustafa, M.W.; Rasid, M.M.; Mirjat, N.H.; Baloch, M.H.; Salisu, S. Optimal Power Flow Controller for Grid-Connected Microgrids using Grasshopper Optimization Algorithm. Electronics 2019, 8, 111. [CrossRef]

5. Al-Saedi, W.; Lachowicz, S.W.; Habibi, D.; Bass, O. Power quality enhancement in autonomous microgrid operation using particle swarm optimization. Int. J. Electr. Power Energy Syst. 2012, 42, 139-149. [CrossRef] 
6. Jumani, T.A.; Mustafa, M.; Rasid, M.M.; Anjum, W.; Ayub, S. Salp Swarm Optimization Algorithm-Based Controller for Dynamic Response and Power Quality Enhancement of an Islanded Microgrid. Processes 2019, 7, 840. [CrossRef]

7. Colson, C.M.; Nehrir, M.H.; Pourmousavi, S.A. Towards real-time microgrid power management using computational intelligence methods. In Proceedings of the IEEE PES General Meeting, Detroit, MI, USA, 24-29 July 2011; IEEE: Piscataway, NJ, USA, 2002; pp. 1-8.

8. Laghari, J.; Mokhlis, H.; Bakar, A.; Mohamad, H. Application of computational intelligence techniques for load shedding in power systems: A review. Energy Convers. Manag. 2013, 75, 130-140. [CrossRef]

9. Das, D.C.; Roy, A.; Sinha, N. GA based frequency controller for solar thermal-diesel-wind hybrid energy generation/energy storage system. Int. J. Electr. Power Energy Syst. 2012, 43, 262-279. [CrossRef]

10. Ngamroo, I. Application of electrolyzer to alleviate power fluctuation in a stand alone microgrid based on an optimal fuzzy PID control. Int. J. Electr. Power Energy Syst. 2012, 43, 969-976. [CrossRef]

11. Ahmadi, S.; Shokoohi, S.; Bevrani, H. A fuzzy logic-based droop control for simultaneous voltage and frequency regulation in an AC microgrid. Int. J. Electr. Power Energy Syst. 2015, 64, 148-155. [CrossRef]

12. Shokoohi, S.; Bevrani, H.; Naghshbandy, A.H. Application of neuro-fuzzy controller on voltage and frequency stability in islanded microgrids. In Proceedings of the Smart Grid Conference (SGC), Tehran, Iran, 17-18 December 2013; pp. 189-194.

13. Hong, C.-M.; Chen, C.-H. Intelligent control of a grid-connected wind-photovoltaic hybrid power systems. Int. J. Electr. Power Energy Syst. 2014, 55, 554-561. [CrossRef]

14. Rezvani, A.; Izadbakhsh, M.; Gandomkar, M. Enhancement of hybrid dynamic performance using ANFIS for fast varying solar radiation and fuzzy logic controller in high speeds wind. J. Electr. Syst. 2015, 11, 11-26.

15. Kamel, R.M.; Chaouachi, A.; Nagasaka, K. Enhancement of micro-grid performance during islanding mode using storage batteries and new fuzzy logic pitch angle controller. Energy Convers. Manag. 2011, 52, 2204-2216. [CrossRef]

16. Kamel, R.M.; Chaouachi, A.; Nagasaka, K. Wind power smoothing using fuzzy logic pitch controller and energy capacitor system for improvement Micro-Grid performance in islanding mode (Retraction of vol 35, pg 2119, 2010). Energy 2015, 85, 688. [CrossRef]

17. Jumani, T.A.; Mustafa, M.W.; Rasid, M.M.; Memon, Z.A. Dynamic response enhancement of grid-tied ac microgrid using salp swarm optimization algorithm. Int. Trans. Electr. Energy Syst. 2019, 30, e12321. [CrossRef]

18. Jumani, T.A.; Mustafa, M.W.; Rasid, M.M.; Mirjat, N.H.; Leghari, Z.H.; Saeed, M.S. Optimal Voltage and Frequency Control of an Islanded Microgrid using Grasshopper Optimization Algorithm. Energies 2018, 11, 3191. [CrossRef]

19. Jumani, T.A.; Mustafa, M.W.; Alghamdi, A.; Rasid, M.M.; Alamgir, A.; Awan, A.B. Swarm Intelligence-based Optimization Techniques for Dynamic Response and Power Quality Enhancement of AC Microgrids-A Comprehensive Review. IEEE Access 2020, 8, 75986-76001. [CrossRef]

20. Larik, R.M.; Mustafa, M.W.; Aman, M.N.; Jumani, T.A.; Sajid, S.; Panjwani, M.K. An improved algorithm for optimal load shedding in power systems. Energies 2018, 11, 1808. [CrossRef]

21. Jumani, T.A.; Mustafa, M.W.; Hussain, Z.; Rasid, M.M.; Saeed, M.S.; Memon, M.M.; Khan, I.; Nisar, K.S. Jaya optimization algorithm for transient response and stability enhancement of a fractional-order PID based automatic voltage regulator system. Alex. Eng. J. 2020. [CrossRef]

22. Khan, I.A.; Alghamdi, A.S.; Jumani, T.A.; Alamgir, A.; Awan, A.B.; Khidrani, A. Salp Swarm Optimization Algorithm-Based Fractional Order PID Controller for Dynamic Response and Stability Enhancement of an Automatic Voltage Regulator System. Electronics 2019, 8, 1472. [CrossRef]

23. Guerrero, J.M.; Loh, P.C.; Lee, T.-L.; Chandorkar, M. Advanced control architectures for intelligent microgrids-Part II: Power quality, energy storage, and AC/DC microgrids. IEEE Trans. Ind. Electron. 2013, 60, 1263-1270. [CrossRef]

24. Guerrero, J.M.; Chandorkar, M.; Lee, T.-L.; Loh, P.C. Advanced control architectures for intelligent microgrids-Part I: Decentralized and hierarchical control. IEEE Trans. Ind. Electron. 2012, 60, 1254-1262. [CrossRef]

25. Hussain, S.M.; Rahim, M.H.; Nadeem, Z.; Fatima, I.; Iqbal, Z.; Asif, S.; Javaid, N. The trends of integrating renewable energy sources: A survey. In Proceedings of the International Conference on Broadband and Wireless Computing, Communication and Applications, Busan, Korea, 18-20 February 2004; pp. 627-636. 
26. Web of Knowledge. Available online: http://webofknowledge.com (accessed on 11 May 2020).

27. Google Scholar. Available online: https://scholar.google.com (accessed on 11 May 2020).

28. Scopus. Available online: https://www.scopus.com (accessed on 11 May 2020).

29. Rezvani, A.; Izadbakhsh, M.; Gandomkar, M. Microgrid dynamic responses enhancement using artificial neural network-genetic algorithm for photovoltaic system and fuzzy controller for high wind speeds. Int. J. Numer. Model. Electron. Netw. Devices Fields 2016, 29, 309-332. [CrossRef]

30. Li, S.; Fairbank, M.; Johnson, C.; Wunsch, D.C.; Alonso, E.; Proao, J.L. Artificial neural networks for control of a grid-connected rectifier/inverter under disturbance, dynamic and power converter switching conditions. IEEE Trans. Neural Netw. Learn. Syst. 2014, 25, 738-750. [CrossRef] [PubMed]

31. Baghaee, H.R.; Mirsalim, M.; Gharehpetian, G.B. Power calculation using RBF neural networks to improve power sharing of hierarchical control scheme in multi-DER microgrids. IEEE J. Emerg. Sel. Top. Power Electron. 2016, 4, 1217-1225. [CrossRef]

32. Bansal, R.; Bhatti, T.; Kothari, D. Automatic reactive power control of isolated wind-diesel hybrid power systems for variable wind speed/slip. Electr. Power Compon. Syst. 2004, 32, 901-912. [CrossRef]

33. Bansal, R.C. Modelling and automatic reactive power control of isolated wind-diesel hybrid power systems using ANN. Energy Convers. Manag. 2008, 49, 357-364. [CrossRef]

34. Alajmi, B.N.; Ahmed, K.H.; Finney, S.J.; Williams, B.W. Fuzzy-logic-control approach of a modified hill-climbing method for maximum power point in microgrid standalone photovoltaic system. IEEE Trans. Power Electron. 2011, 26, 1022-1030. [CrossRef]

35. Patcharaprakiti, N.; Premrudeepreechacharn, S.; Sriuthaisiriwong, Y. Maximum power point tracking using adaptive fuzzy logic control for grid-connected photovoltaic system. Renew. Energy 2005, 30, 1771-1788. [CrossRef]

36. Alajmi, B.N.; Ahmed, K.H.; Finney, S.J.; Williams, B.W. A maximum power point tracking technique for partially shaded photovoltaic systems in microgrids. IEEE Trans. Ind. Electron. 2013, 60, 1596-1606. [CrossRef]

37. Marzband, M.; Sumper, A.; Gomis-Bellmunt, O.; Pezzini, P.; Chindris, M. Frequency control of isolated wind and diesel hybrid microgrid power system by using fuzzy logic controllers and PID controllers. In Proceedings of the 11th International Conference on Electrical Power Quality and Utilisation (EPQU), Lisbon, Portugal, 17-19 October 2011; pp. 1-6.

38. Rashed, M.; Elmitwally, A.; Kaddah, S. New control approach for a PV-diesel autonomous power system. Electr. Power Syst. Res. 2008, 78, 949-956. [CrossRef]

39. Diaz, N.L.; Dragicevic, T.; Vasquez, J.C.; Guerrero, J.M. Fuzzy-logic-based gain-scheduling control for state-of-charge balance of distributed energy storage systems for DC microgrids. In Proceedings of the Applied Power Electronics Conference and Exposition (APEC), 2014 Twenty-Ninth Annual IEEE, Fort Worth, TX, USA, 16-20 March 2014; pp. 2171-2176.

40. Li, X.; Song, Y.-J.; Han, S.-B. Frequency control in micro-grid power system combined with electrolyzer system and fuzzy PI controller. J. Power Sources 2008, 180, 468-475. [CrossRef]

41. Li, X.; Li, N.; Jia, X.; Hui, D. Fuzzy logic based smoothing control of wind/PV generation output fluctuations with battery energy storage system. In Proceedings of the International Conference on Electrical Machines and Systems (ICEMS), Beijing, China, 20-23 August 2011; pp. 1-5.

42. Chamorro, H.; Ramos, G. Microgrid central fuzzy controller for active and reactive power flow using instantaneous power measurements. In Proceedings of the Power and Energy Conference at Illinois (PECI), 2011 IEEE, Urbana, IL, USA, 25-26 February 2011; pp. 1-6.

43. Senjyu, T.; Datta, M.; Yona, A.; Sekine, H.; Funabashi, T. A new method for smoothing output power fluctuations of PV system connected to small power utility. In Proceedings of the ICPE'07 7th Internatonal Conference on Power Electronics, Daegu, Korea, 22-26 October 2007; pp. 829-834.

44. Vigneysh, T.; Kumarappan, N. Autonomous operation and control of photovoltaic/solid oxide fuel cell/battery energy storage based microgrid using fuzzy logic controller. Int. J. Hydrog. Energy 2016, 41, 1877-1891. [CrossRef]

45. Salhi, I.; Doubabi, S.; Essounbouli, N. Fuzzy control of micro hydro power plants. In Proceedings of the 5th IET International Conference on Power Electronics, Machines and Drives (PEMD 2010), Brighton, UK, 19-21 April 2010. 
46. Benachaiba, C.; Haidar, A.M.; Habab, M.; Abdelkhalek, O. Smart control of UPCQ within microgrid energy system. Energy Procedia 2011, 6, 503-512. [CrossRef]

47. Nair, D.R.; Devi, S.; Nair, M.G.; Ilango, K. Tariff based fuzzy logic controller for active power sharing between microgrid to grid with improved power quality. In Proceedings of the International Conference on Energy Efficient Technologies for Sustainability (ICEETS), Nagercoil, India, 7-8 April 2016; pp. 406-409.

48. Farsadi, M.; Shahrak, A.G.; Tabrizi, S.D. DVR with fuzzy logic controller and photovoltaic for improving the operation of wind farm. In Proceedings of the 8th International Conference on Electrical and Electronics Engineering (ELECO), Bursa, Turkey, 28-30 November 2013; pp. 191-195.

49. Ramasamy, M.; Thangavel, S. Photovoltaic based dynamic voltage restorer with energy conservation capability using fuzzy logic controller. In Proceedings of the International Conference on Emerging Trends in Science, Engineering and Technology (INCOSET), Tiruchirappalli, Tamilnadu, India, 13-14 December 2012; pp. 485-492.

50. Sefa, I.; Altin, N.; Ozdemir, S.; Kaplan, O. Fuzzy PI controlled inverter for grid interactive renewable energy systems. IET Renew. Power Gener. 2015, 9, 729-738. [CrossRef]

51. Mukhopadhyay, B.; Mandal, R.K. Application of Artificial Intelligence-Based Techniques in Controlling the STATCOM Used for Compensation for Voltage Dips in DFIG-Based Grid-Connected Wind Power System. In Advances in Smart Grid and Renewable Energy; Springer: New York, NY, USA, 2018; pp. 177-189.

52. Izadbakhsh, M.; Rezvani, A.; Gandomkar, M. Improvement of microgrid dynamic performance under fault circumstances using ANFIS for fast varying solar radiation and fuzzy logic controller for wind system. Arch. Electr. Eng. 2014, 63, 551-578. [CrossRef]

53. Vafaei, S.; Rezvani, A.; Gandomkar, M.; Izadbakhsh, M. Enhancement of grid-connected photovoltaic system using ANFIS-GA under different circumstances. Front. Energy 2015, 9, 322-334. [CrossRef]

54. Kamel, R.M.; Chaouachi, A.; Nagasaka, K. Micro-grid dynamic response enhancement using new proportional integral wind turbine pitch controller and neuro-fuzzy photovoltaic maximum power point tracking controller. Electr. Power Compon. Syst. 2009, 38, 212-239. [CrossRef]

55. Hassan, S.Z.; Li, H.; Kamal, T.; Arifoğlu, U.; Mumtaz, S.; Khan, L. Neuro-Fuzzy Wavelet Based Adaptive MPPT Algorithm for Photovoltaic Systems. Energies 2017, 10, 394. [CrossRef]

56. Chettibi, N.; Mellit, A. Intelligent control strategy for a grid connected PV/SOFC/BESS energy generation system. Energy 2018, 147, 239-262. [CrossRef]

57. Khorramabadi, S.S.; Bakhshai, A. Critic-based self-tuning PI structure for active and reactive power control of VSCs in microgrid systems. IEEE Trans. Smart Grid 2015, 6, 92-103. [CrossRef]

58. García, P.; García, C.A.; Fernández, L.M.; Llorens, F.; Jurado, F. ANFIS-based control of a grid-connected hybrid system integrating renewable energies, hydrogen and batteries. IEEE Trans. Ind. Inform. 2014, 10, 1107-1117. [CrossRef]

59. Renduchintala, U.K.; Pang, C. Neuro-fuzzy based UPQC controller for Power Quality improvement in micro grid system. In Proceedings of the Transmission and Distribution Conference and Exposition (T\&D), 2016 IEEE/PES, Dallas, TX, USA, 3-5 May 2016; pp. 1-5.

60. Daraban, S.; Petreus, D.; Morel, C. A novel MPPT (maximum power point tracking) algorithm based on a modified genetic algorithm specialized on tracking the global maximum power point in photovoltaic systems affected by partial shading. Energy 2014, 74, 374-388. [CrossRef]

61. Ramaprabha, R.; Mathur, B. Genetic algorithm based maximum power point tracking for partially shaded solar photovoltaic array. Int. J. Res. Rev. Inf. Sci. 2012, 161-163.

62. Razavi, F.; Torani, R.; Askarian, I.; Asgharizadeh, A.; Masoomi, N. Optimal design of islanded microgrid using genetic algorithm. In Proceedings of the International Conference on Genetic and Evolutionary Methods (GEM), Las Vegas, NV, USA, 12-15 July 2010; p. 1.

63. Abdel-Hamed, A.M.; Ellissy, A.E.-E.K.; El-Wakeel, A.S.; Abdelaziz, A.Y. Optimized control scheme for frequency/power regulation of microgrid for fault tolerant operation. Electr. Power Compon. Syst. 2016, 44, 1429-1440. [CrossRef]

64. Lotfy, M.E.; Senjyu, T.; Farahat, M.A.-F.; Abdel-Gawad, A.F.; Lei, L.; Datta, M. Hybrid Genetic Algorithm Fuzzy-Based Control Schemes for Small Power System with High-Penetration Wind Farms. Appl. Sci. 2018, 8, 373. [CrossRef] 
65. Wies, R.W.; Chukkapalli, E.; Mueller-Stoffels, M. Improved frequency regulation in mini-grids with high wind contribution using online genetic algorithm for PID tuning. In Proceedings of the PES General Meeting| Conference \& Exposition, 2014 IEEE, National Harbor, MD, USA, 27-31 July 2014; pp. 1-5.

66. Varma, A.; Sharma, N.K.; Gawre, S.K. Reactive Reserve Management based Voltage Stability Enhancement using Genetic Algorithm. In Proceedings of the 2018 IEEE International Students' Conference on Electrical, Electronics and Computer Science (SCEECS), Bhopal, India, 24-25 February 2018; pp. 1-6.

67. Suresh, S.; Kannanand, S.; Manikandan, B. Power quality enhancement employing genetic algorithm based asymmetrical multilevel inverter. In Proceedings of the 2016 International Conference on Circuit, Power and Computing Technologies (ICCPCT), Nagercoil, India, 18-19 March 2016; pp. 1-8.

68. Kalogirou, S.A. Artificial neural networks in renewable energy systems applications: A review. Renew. Sustain. Energy Rev. 2001, 5, 373-401. [CrossRef]

69. Bansal, R.; Bhatti, T.; Kothari, D. Automatic reactive power control of wind-diesel-micro-hydro autonomous hybrid power systems using ANN tuned static VAr compensator. In Proceedings of the Large Engineering Systems Conference on Power Engineering, Montreal, QC, Canada, 7-9 May 2003; pp. 182-188.

70. Isanta Navarro, R. Study of a neural network-based system for stability augmentation of an airplane. 2013. Available online: https://upcommons.upc.edu/handle/2099.1/20296 (accessed on 11 May 2020).

71. Mendel, J.; Hagras, H.; Tan, W.-W.; Melek, W.W.; Ying, H. Introduction to Type-2 Fuzzy Logic Control: Theory and Applications; John Wiley \& Sons: New York, NY, USA, 2014.

72. Zadeh, L.A. Fuzzy sets. In Fuzzy Sets, Fuzzy Logic, and Fuzzy Systems: Selected Papers by Lotfi a Zadeh; World Scientific: Singapore, 1996; pp. 394-432.

73. Vieira, J.; Dias, F.M.; Mota, A. Neuro-fuzzy systems: A survey. In Proceedings of the 5th WSEAS NNA International Conference on Neural Networks and Applications, Udine, Italia, 27 March 2004.

74. Salam, Z.; Ahmed, J.; Merugu, B.S. The application of soft computing methods for MPPT of PV system: A technological and status review. Appl. Energy 2013, 107, 135-148. [CrossRef]

75. Herrera, F.; Lozano, M.; Verdegay, J.L. Tuning fuzzy logic controllers by genetic algorithms. Int. J. Approx. Reason. 1995, 12, 299-315. [CrossRef]

76. Babahajyani, P.; Habibi, F.; Bevrani, H. An on-line pso-based fuzzy logic tuning approach: Microgrid frequency control case study. In Handbook of Research on Novel Soft Computing Intelligent Algorithms: Theory and Practical Applications; IGI Global: Hershey, PA, USA, 2014; pp. 589-616.

77. Chaiyatham, T.; Ngamroo, I. A bee colony optimization based-fuzzy logic-PID control design of electrolyzer for microgrid stabilization. Int. J. Innov. Comput. Inf. Control 2012, 8, 6049-6066.

78. Pan, I.; Das, S. Fractional order fuzzy control of hybrid power system with renewable generation using chaotic PSO. ISA Trans. 2016, 62, 19-29. [CrossRef]

79. Kumar, A.S.; Rajasekar, S.; Raj, P.A.-D.-V. Power quality profile enhancement of utility connected microgrid system using ANFIS-UPQC. Procedia Technol. 2015, 21, 112-119. [CrossRef]

80. Jang, J.-S. ANFIS: Adaptive-network-based fuzzy inference system. Ieee Trans. Syst. ManCybern. 1993, 23, 665-685. [CrossRef]

81. Jang, J.-S.R.; Sun, C.-T.; Mizutani, E. Neuro-fuzzy and soft computing-a computational approach to learning and machine intelligence [Book Review]. IEEE Trans. Autom. Control 1997, 42, 1482-1484. [CrossRef]

82. Atmaca, H.; Cetisli, B.; Yavuz, H.S. The comparison of fuzzy inference systems and neural network approaches with ANFIS method for fuel consumption data. In Proceedings of the Second International Conference on Electrical and Electronics Engineering Papers ELECO, Rome, Italy, 22-23 July 2019.

83. Ghomsheh, V.S.; Shoorehdeli, M.A.; Teshnehlab, M. Training ANFIS structure with modified PSO algorithm. In Proceedings of the MED'07. Mediterranean Conference on Control \& Automation, Athens, Greece, 27-29 June 2007; pp. 1-6.

84. Cárdenas, J.J.; Garcia, A.; Romeral, J.; Kampouropoulos, K. Evolutive ANFIS training for energy load profile forecast for an IEMS in an automated factory. In Proceedings of the IEEE 16th Conference on Emerging Technologies \& Factory Automation (ETFA), Toulouse, France, 5-9 September 2011; pp. 1-8.

85. Muthuramalingam, M.; Manoharan, P. Comparative analysis of distributed MPPT controllers for partially shaded stand alone photovoltaic systems. Energy Convers. Manag. 2014, 86, 286-299. [CrossRef]

86. Hussain, K.; Salleh, M.N.M. Optimization of fuzzy neural network using APSO for predicting strength of Malaysian SMEs. In Proceedings of the Control Conference (ASCC), 2015 10th Asian, Kota Kinabalu, Malaysia, 31 May-3 June 2015; pp. 1-6. 
87. Karaboga, D.; Kaya, E. Training ANFIS using artificial bee colony algorithm. In Proceedings of the IEEE International Symposium on Innovations in Intelligent Systems and Applications (INISTA), Albena, Bulgaria, 19-21 June 2013; pp. 1-5.

88. Ibrahim, W.A.; Morcos, M.M. Artificial intelligence and advanced mathematical tools for power quality applications: A survey. IEEE Trans. Power Deliv. 2002, 17, 668-673. [CrossRef]

89. Holland, J.H. Adaptation in Natural and Artificial Systems: An Introductory Analysis with Applications to Biology, Control, and Artificial Intelligence; MIT Press: Cambridge, MA, USA, 1992.

90. Chen, H. Machine learning for information retrieval: Neural networks, symbolic learning, and genetic algorithms. J. Assoc. Inf. Sci. Technol. 1995, 46, 194-216. [CrossRef]

91. Amjad, A.M.; Salam, Z. A review of soft computing methods for harmonics elimination PWM for inverters in renewable energy conversion systems. Renew. Sustain. Energy Rev. 2014, 33, 141-153. [CrossRef]

92. Fathima, A.H.; Palanisamy, K. Optimization in microgrids with hybrid energy systems-A review. Renew. Sustain. Energy Rev. 2015, 45, 431-446. [CrossRef]

93. El-Hosseini, M.A.; Hassanien, A.E.; Abraham, A.; Al-Qaheri, H. Genetic annealing optimization: Design and real world applications. In Proceedings of the 2008 Eighth International Conference on Intelligent Systems Design and Applications, Kaohsiung, Taiwan, 26-28 November 2008; pp. 183-188.

94. Garg, H. A hybrid PSO-GA algorithm for constrained optimization problems. Appl. Math. Comput. 2016, 274, 292-305. [CrossRef]

95. Hamadneh, N.; Khan, W.A.; Sathasivam, S.; Ong, H.C. Design optimization of pin fin geometry using particle swarm optimization algorithm. PLoS ONE 2013, 8, e66080. [CrossRef]

96. Shokoohi, S.; Sabori, F.; Bevrani, H. Secondary voltage and frequency control in islanded microgrids: Online ANN tuning approach. In Proceedings of the Smart Grid Conference (SGC), Tehran, Iran, 9-10 December 2014; pp. 1-6.

97. Messai, A.; Mellit, A.; Guessoum, A.; Kalogirou, S. Maximum power point tracking using a GA optimized fuzzy logic controller and its FPGA implementation. Solar Energy 2011, 85, 265-277. [CrossRef]

98. Jurado, F.; Ortega, M.; Carpio, J. Power quality enhancement in fuel cells using genetic algorithms and ANFIS architecture. In Proceedings of the IEEE International Symposium on Industrial Electronics, Hangzhou, China, 28-31 May 2006; pp. 757-762.

99. Nandar, C.S.A. Robust PI control of smart controllable load for frequency stabilization of microgrid power system. Renew. Energy 2013, 56, 16-23. [CrossRef]

100. Lotfy, M.E.; Senjyu, T.; Farahat, M.A.-F.; Abdel-Gawad, A.F.; Yona, A. A frequency control approach for hybrid power system using multi-objective optimization. Energies 2017, 10, 80. [CrossRef]

101. Lotfy, M.E.; Senjyu, T.; Farahat, M.A.; Abdel-Gawad, A.F.; Yona, A. Control Scheme of Hybrid Wind-Diesel System with SMES Using NSGA-II. J. Energy Power Eng. 2017, 11, 204-213. 